Portland State University

PDXScholar

7-29-1977

\title{
Determination of Mercury by Photoacoustic Spectroscopy
}

Robert Allen Cary

Portland State University

Follow this and additional works at: https://pdxscholar.library.pdx.edu/open_access_etds

Part of the Chemistry Commons

Let us know how access to this document benefits you.

Recommended Citation

Cary, Robert Allen, "Determination of Mercury by Photoacoustic Spectroscopy" (1977). Dissertations and Theses. Paper 2476.

https://doi.org/10.15760/etd.2473

This Thesis is brought to you for free and open access. It has been accepted for inclusion in Dissertations and Theses by an authorized administrator of PDXScholar. Please contact us if we can make this document more accessible: pdxscholar@pdx.edu. 
AN ABSTRACT OF THE THESIS OF Robert Allen Cary for the Master of Science in. Chemistry presented July 29, 1977.

Title: Determination of Mercury by Photoacoustic Spectroscopy

APPROVED BY MEMBERS OF THE THESIS COMMITTEE:
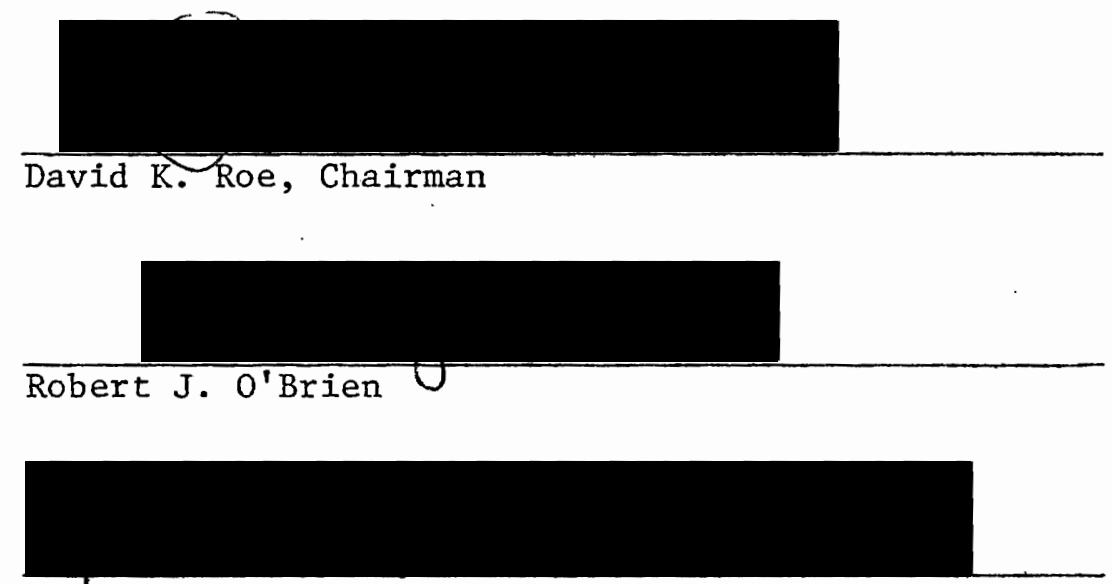

M.B. Silverman

A new detector for atomic spectroscopy was developed based on the photoacoustic principle. A simple system was constructed based on this detector and applied to the trace analysis of mercury. The detection limit was found to be about $0.2 \mu \mathrm{g} / \mathrm{I}$ of mercury with a one milliliter sample. 
DETERMINATION OF MERCURY BY PHOTOACOUSTIC SPECTROSCOPY

by

ROBERT ALLEN CARY

A thesis submitted in partial fulfillment of the requirements for the degree of

\section{MASTER OF SCIENCE \\ in \\ CHEMISTRY}

Portland State University

1977 
TO THE OFFICE OF GRADUATE STUDIES AND RESEARCH:

The members of the Committee approve the thesis of

Robert Allen Cary presented July 29, 1977.

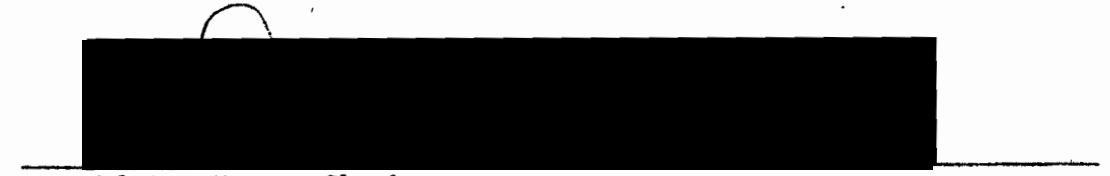

David K. Roe, Chairman

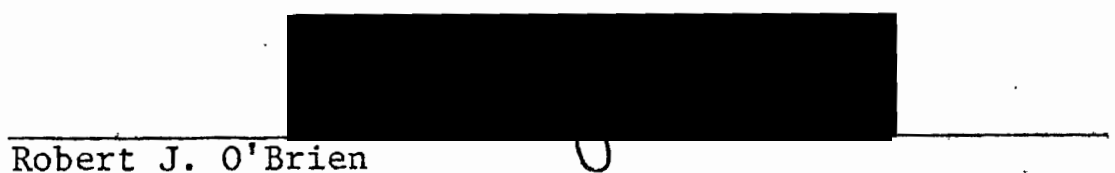

Robert J. O'Brien

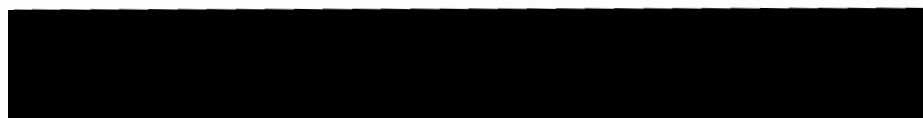

M,B! Silverman

APPROVED :

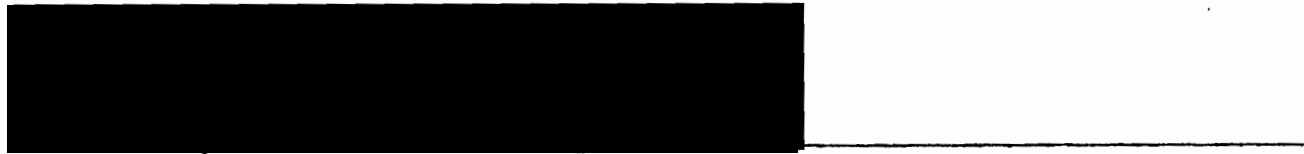

Gary L. Gard, Department of Chemistry

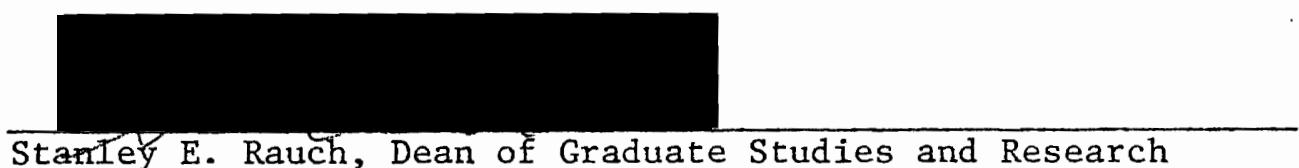




\section{ACKNOWLEDGMENTS}

I would like to thank Jim Johnson, John Kennish, Ron Haak and An McFarlane for the help they have given me throughout this project.

Also, thanks to Lee Thannum and Brian McLaughlin of the Electronics Shop who went out of their way many times to explain. And, to my research advisor, Dr. David Roe, goes a great deal of gratitude for being the perfect advisor for the project. And, of course, to Sue and Ben. 
PAGE

ACKNOWLEDGMENTS . . . . . . . . . . . . . 111 LIST OF TABLES . . . . . . . . . . . . . $\mathrm{v}$ LIST OF FIGURES . . . . . . . . . . . . . . . . vi vi

CHAPTER

I INTRODUCTION . . . . . . . . . . . . 1

II THEORY . . . . . . . . . . . . 3

III EXPERTMENTAL .............. 8

IV RESULTS AND DISCUSSION . . . . . . . 16

APPENDIX A

Collision of $\mathrm{Hg}$ Atoms with $\mathrm{N}_{2}$ Molecules. . 20 APPENDIX B

Lamp Power Supply. . . . . . . . . . 22 APPENDIX C

Amplifier Circuits . . . . . . . . . 23 APPENDIX D

SC/MP Pulse Controller . . . . . . . 26

BIBLIOGRAPHY. . . . . . . . . . . . . 31 
LIST OF TABLES

TABLE

PAGE

I General Program for Control Pulses . . . $2 y$

II Program for $22.093 \mathrm{~Hz}$ Pulses... . . 30 


\section{LIST OF FIGURES}

\section{FIGURE}

PAGE

1 Photoacoustic Detection Systems . . . . . 9

2 Detection Cell. ............ 10

3 Microphone. . ............. 12

4 Sample Reduction Chamber. . . . . . . . 15

5 Signal Response vs. Mercury Concentration . . 19

6 Lamp Power Supply . . . . . . . . . . 22

7 Preamplifier. . . . . . . . . . . 23

8 Twin-T Filter . . . . . . . . . 23

9 Lock-in Amplifier . . . . . . . . 25

10 Phase Relationship of Pulses. . . . . . . 26 
CHAPTER I

\section{INTRODUCTION}

Photoacoustic spectroscopy (sometimes referred to as optoacoustic spectroscopy) is a technique in which a substance absorbs a pulsed beam, of light and transforms the absorbed energy into thermal energy of the surrounding gas. Within an enclosure of fixed volume, this slight temperature increase will produce a corresponding pressure increase, which will then pulse at the frequency of the impinging Iight. This pulsing pressure is acoustic energy, or "sound," and could, in theory, be sensed by a microphone.

The origins of this method are in the work done by Alexander Graham Bell and John Tynda1I in the $1880^{\prime} \mathrm{s}$. Short histories can be found in the articles of Harshbarger and Robin (1), Adams, et al. (2), Rosengren (3) and Kreuzer (4). But it was not until the late 1960's that it became useful as an analytical technique. This was partly due to development of electronic means for detecting small signals, but was especially due to the development of intense monochromatic light sources such as tunable dye lasers.

Trace analysis using photoacoustic spectroscopy (PAS) has mostly been applied to measurements in the gas phase using visible and infrared radiation from lasers $(4,5,6,7,8)$. It has been shown to be an effective method for measuring trace gases in the atmosphere which have very small absorption coefficients, such as n-butane (8) and No, 
down to $1.0 \times 10^{7}$ molecules $\mathrm{cm}^{-3}(6)$.

Some work has also been done studying the absorption of solids using PAS $(8,9,10,11,12,13,14)$. This is usually done by using a high wattage continuum source such as a xenon lamp in conjunction with a scanning monochromater. Studies have even been done on nonfluorescent absorbers in liquid solutions by using a piezoelectric ceramic tube which uniquely serves as both the sample holding cell and pressure sensor for the 1ight-pulse generated pressure fluctuations (5). PAS has also been used as a tool for studying various reaction mechanisms as well as several other properties of materials. Harshbarger and Robin (16) studied the quenching of iodine atoms by oxygen. Robin and Kuebler (17) also employed it to study relaxation of excited states of aromatic ketones. Wetsel and McDonald (18) have even demonstrated the possibility of determining absolute optical absorption coefficients using PAS.

However, there has been very little use of PAS in the ultraviolet region compared to its use in the visible and IR. Some work has been done by Robin (5) using UV light to study molecular gases. But, at present there has been no published work using PAS for the study of atomic absorption. 


\section{CHAPTER II}

\section{THEORY}

The research objective was to determine the feasibility of detecting metals with high vapor pressures, such as mercury, by a technique which is essentially a combination of atomic fluorescence spectrometry (AFS) and photoacoustic spectroscopy (PAS). A pulsed electromagnetic energy is absorbed by the vapor form of the element, causing it to become electronically excited. In the presence of a high pressure of inert gas such as nitrogen, the excited atom then loses its excess energy through collisional processes, which in effect, heats the gas slightly. This small temperature rise causes a corresponding pressure increase which will pulse at the same rate as the impinging light.

The situation might be considered analogous to atomic fluorescence spectrometry, which has been adequately described by Winefordner and E1ser (19) and Kirkbright and Sargent (20). In order for a signal to be detected, a photon of electromagnetic radiation must first be absorbed by the atom. This will cause an electronic excitation of the atom with an energy increase corresponding to the energy of the absorbed photon.

For metal atoms, the bandwidth of energy which can be absorbed is very narrow, typically in the range of $0.001-0.005 \mathrm{~nm}$. Thus, if the proper frequency of radiation is used, one can very selectively excite only the species of interest. This could be represented for 
the mercury atom as:

$$
\mathrm{Hg}+\mathrm{h \nu}(253.7 \mathrm{~nm}) \rightarrow \mathrm{Hg} *
$$

where $\mathrm{Hg}$ represents the ${ }^{{ }^{1}} \mathrm{~S}_{\mathrm{O}}$ ground state atom and $\mathrm{Hg} *$ is the excited $3 P_{1}$ state.

There are several ways for this excited atom to return to its ground state. Two are of main interest here. In the absence of any collisional processes such as foreign atoms or container walls, the atom may spontaneously re-emit the absorbed photon randomly and return to the ground state.

$$
\mathrm{Hg} * \rightarrow \mathrm{Hg}+\mathrm{hv}(253.7 \mathrm{~nm})
$$

This is termed resonance fluorescence and is of primary interest in AFS. Any process which reduces this reaction will obviously reduce the signal which is detected. The lifetime of the excited state is one important factor in AFS and for $\mathrm{Hg} *\left({ }^{3} \mathrm{P}_{1}\right)$ this is on the order of $1 \times 10^{-7}$ seconds.

If, however, the excited atom collides with a foreign atom or molecule before fluorescing, the excess energy may be transferred to this other body as energy of vibration, rotation, translation or some combination of these. This energy will eventually become translational energy, which in effect, raises the temperature of the gas.

This is termed collisional quenching and is of primary concern in photoacoustic spectroscopy. Conditions which favor this process are high pressures of foreign molecules, especially those which are known to be efficient quenchers. For a gas such as nitrogen at one 
atmosphere pressure, it can be calculated from kinetic theory (see Appendix A) that an efficient quenching collision occurs on the order of every $5 \times 10^{-10}$ seconds. Therefore, an excited $\mathrm{Hg}$ atom will collide with about 200 nitrogen molecules, any one of which can absorb the excess energy before the atom can fluoresce. Under these conditions, which are, in fact, hard to prevent, a system which measures the absorbed energy of excitation that has been collisionally quenched may be an effective analytical tool. This is exactly what photoacoustic spectroscopy does.

Since it is the absorbed light energy which eventually causes the acoustic signal, an analysis of absorption should now be examined.

Under Beer's 1aw, the electromagnetic energy absorbed as light passing through a cell containing an absorbing species can be shown to be:

$$
I_{A b}=I_{0}[1-\exp (-K C)]
$$

where

$$
\begin{aligned}
I_{A b}= & \text { energy absorbed by the species } \\
I_{0}= & \text { incident energy entering the cell } \\
\mathrm{C}= & \text { concentration of the absorbing species } \\
\mathrm{K}= & \text { a constant which includes the ab- } \\
& \text { sorption coefficient of the absorber } \\
& \text { as well as a constant for the cell } \\
& \text { geometry such as length and incident } \\
& \text { angle of the light. }
\end{aligned}
$$

This absorbed energy can now be fluoresced or quenched. The intensity of fluoresced energy is given by the equation (ref. 20) 


$$
I_{F}=I_{0} w \frac{\Omega}{4 \pi} A_{T} \phi
$$

where $\quad I_{F}=$ energy fluoresced

$$
\begin{aligned}
\mathrm{w}= & \text { line width of exciting radiation } \\
\Omega= & \text { solid angle over which the excited fluor- } \\
& \text { escence is detected } \\
\mathrm{A}_{\mathrm{T}}= & \text { absorption factor for the spectral line } \\
& \text { (which depends on path length as well as } \\
& \text { atom concentration) } \\
=\quad & \text { fluorescence yield, i.e. fraction of ab- } \\
& \text { sorbed photons which are re-emitted as } \\
& \text { radiation. }
\end{aligned}
$$

If fluorescence and quenching are assumed to be the only forms of deactivation, then the energy deactivated by collisional quenching will be the difference in the energy absorbed and the energy fluoresced.

$$
I_{q}=I_{A b}-I_{F}
$$

By using conditions under which $\phi$ is very small, for example high pressures of efficient quenching molecules, the fluoresced energy will be small and essentially all the absorbed energy will be quenched. Thus, the absorbed light energy essentially becomes a temperature increase, which corresponds to a pressure increase within the cell. Assuming that the pressure transducer and amplification respond linearly, a signal, $\mathrm{S}$, which is then proportional to the absorbed. power, $I_{\mathrm{Ab}}$ will then be detected. With $K^{\prime}$ as the constant of proportionality, so that $S=K^{\prime} I_{A b}$, Equation [1] gives:

$$
S=K^{\prime} I_{0}[1-\exp (-K C)]
$$


This equation can be examined in the two Iimiting cases, where $\mathrm{KC}$ is very large and very small.
1) For large $\mathrm{KC}: \quad \exp (-\mathrm{KC}) \cong 0$ so that $\quad S \cong K^{\prime} I_{0}$
2) For small KC: $\exp (-K C) \cong 1-K C$ so that $\quad S \cong K^{\prime} I_{O} K C$

Therefore, for concentrations above a certain value, essentially all the entering power is absorbed and the signal will only be proportional to the intensity of the light of the proper frequency which enters the cell.

For small concentrations, however, the signal will be directly related to the concentration as well as light intensity. It is the dependence on light intensity which makes this technique attractive for PAS as it is in AFS, because for very small concentrations, one can receive an increased signal if the light intensity can be increased. 
CHAPTER III

\section{EXPERIMENTAL}

The photoacoustic system used in the research is represented by Figure 1.

The d.c. lamp power supply (see Appendix B) was a 550 V.d.c. source which could be pulsed by an external signal. It was possible to change the output to $1100 \mathrm{~V} . d . c$. if desired. It contained settings for 6 different lamp currents. The lamp could also be operated in a continuous as well as pulsed mode.

The light source used was a low vapor pressure mercury lamp (G.E., Cat. 非 29924). Approximately $95 \%$ of the light output of this lamp consisted of the $253.7 \mathrm{~nm}$. Iine of $\mathrm{Hg}$. Possibly a mercury hollow cathode lamp could be used for the source.

If desired, the light could be focused into the cell by a Suprasil lens with a focal length of $50 \mathrm{~mm}$. The light then entered the sample cell (see Fig. 2) through a quartz window and any unabsorbed radiation passed out through a similar quartz window at the back. The sample cell was constructed from a $10 \mathrm{~mm}$ standard wall Pyrex tubing approximately $6.8 \mathrm{~cm}$ long. The quartz windows were attached to the ends of the cell using clear silicone cement.

Sample entry and exit were achieved by two $0.3 \mathrm{~mm}$ i.d. capillary tubes approximately $9 \mathrm{~cm}$ long. These were attached about $0.5 \mathrm{~cm}$ from each end of the cell body. The small size and long length of these 


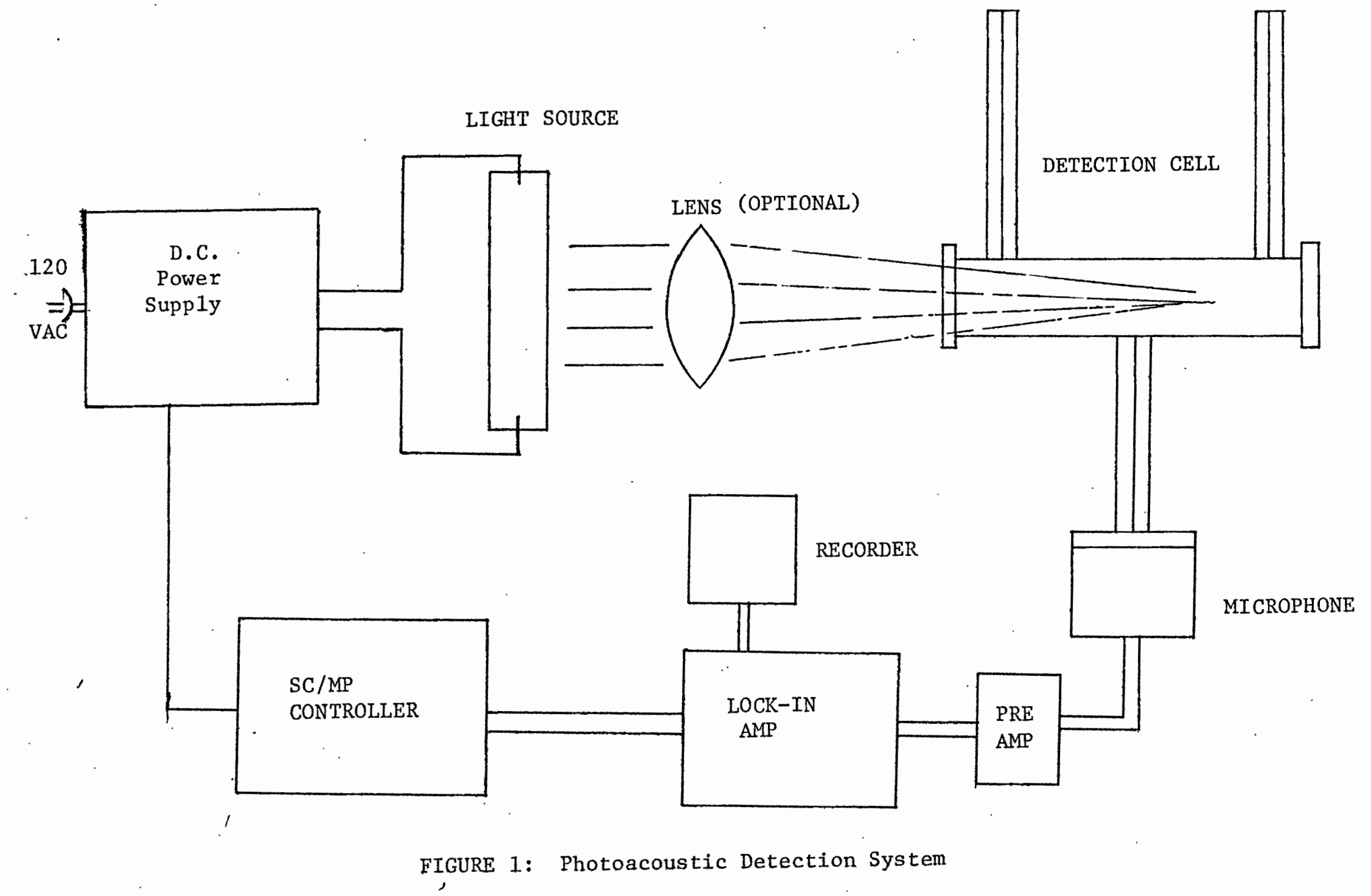




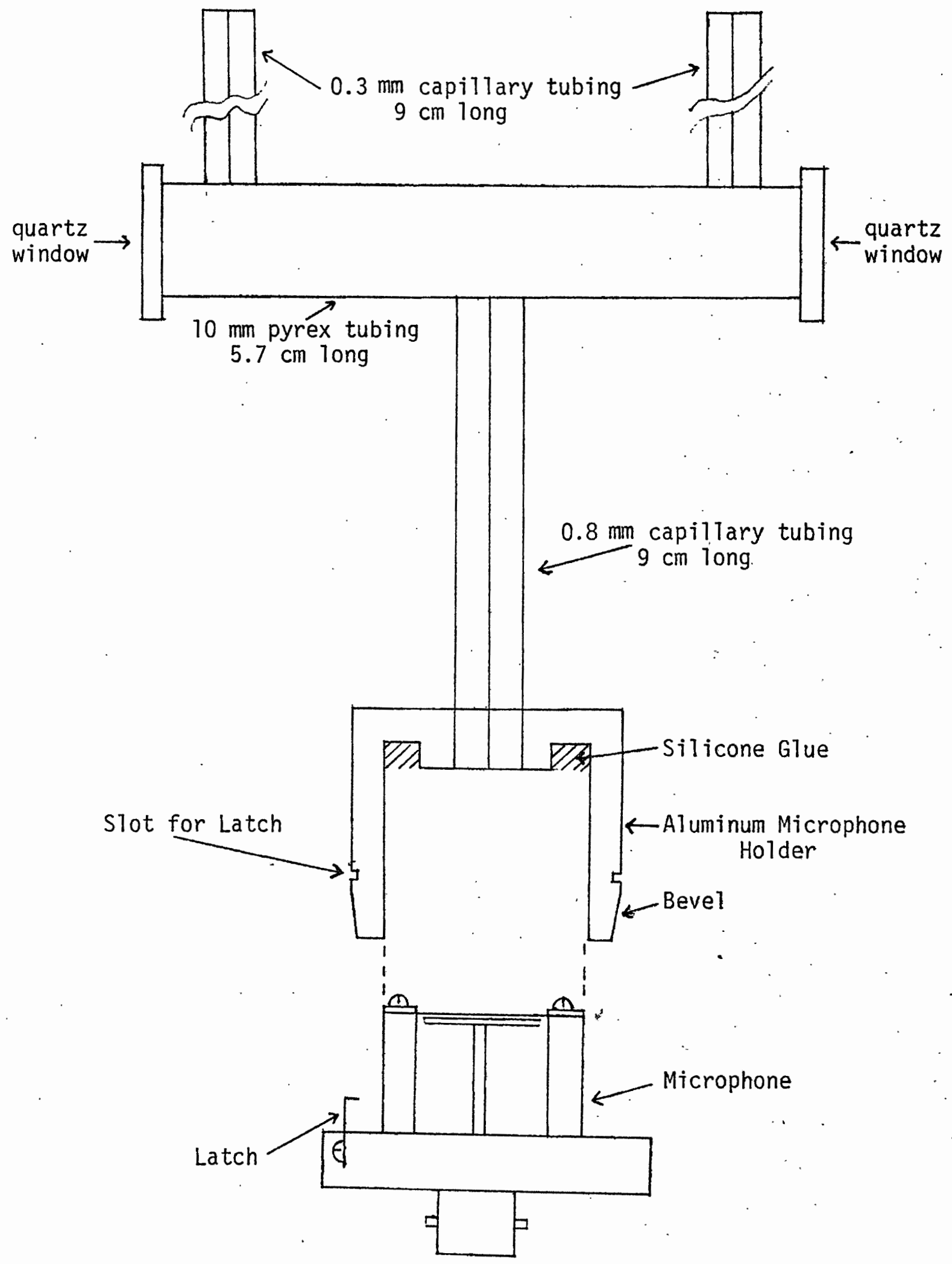

Figure 2: Detection Cell 
capillaries provided sufficient resistance to prevent significant acoustic power loss outside the cell.

Connection of the cell to the microphone was provided by a capillary with $0.8 \mathrm{~mm}$ i.d. and about $9 \mathrm{~cm}$ in length. This larger size capillary offered a low enough resistance to allow the pressure pulse to be transmitted to the microphone chamber without much attenuation (21). This was done in order to allow the option of heating the cell without heating the microphone. The microphone capillary. was attached to an aluminum microphone housing with silicone cement. The microphone (see Fig. 3) was constructed around a BNC connector to facilitate connection to the preamplifier. The microphone was an electret type with its diaphragm made of 0.5 mil mylar film with a thin metalized coating on one surface.

In order to charge the film, it was placed on a flat glass surface with the metal side down and a Tesla coil waved above it (2-3") for about two minutes (22). Care must be exercised at this point in order not to puncture the film surface with the discharge. The film is then stretched across the top surface of the microphone with the metal side up and attached with the brass holding ring. At this point, the microphone should give a response of several $\mathrm{mV}$ on an oscillor scope when addressed in a normal speaking voice.

The amplifier system (see Appendix C) consisted of a narrow bandpass preamp, a lock-in amplifier with optional gain and an adjustable gain d.c. amplifier stage. The final output was then monitored with a chart recorder with a variable full scale reading of $10 \mathrm{mV}$ to $100 \mathrm{~V}$. 


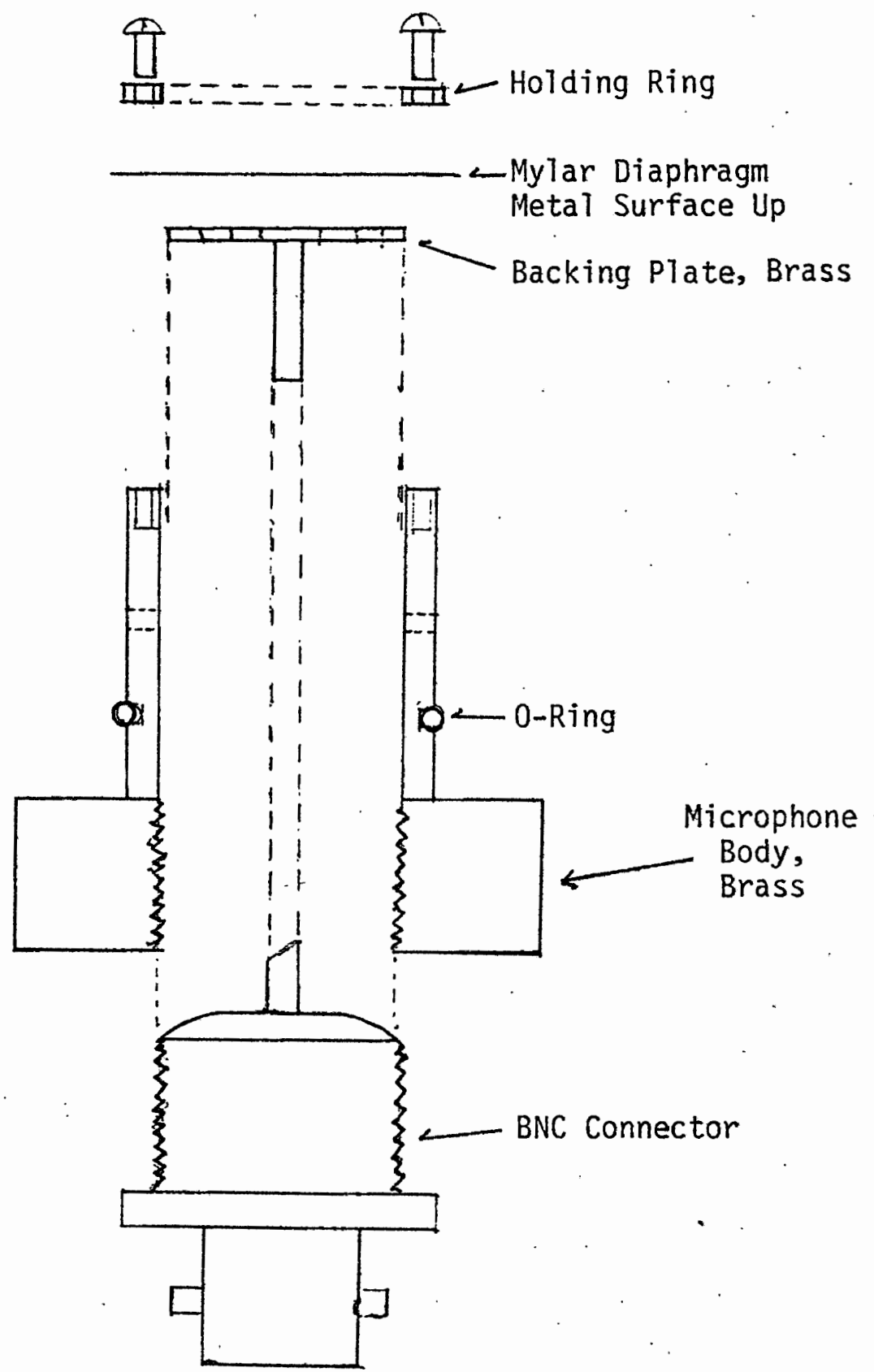

Figure 3: Microphone 
The controlling pulses for the light and lock-in amplifier were generated by a SC/MP microprocessor system (see Appendix D). This assured that only signals with exactly the frequency of the light source were amplified. There was also flexibility in the phase angle relationship of the detected signal with respect to the pulsing signal. Also, the duty cycle of the light pulse was easily adjustable.

However, both the lock-in amplifier and light pulses had to be at precisely the same frequency as the narrow band-pass preamp. One further advantage in using the SC/MP was that the output signals could be attenuated with a resistor network and applied to the preamp input while monitoring the output on an oscilloscope. Then simple changes in software programming allowed the period of the applied signal to be changed by as little as 16 microseconds. At $22 \mathrm{~Hz}$, this corresponds to increments of $0.008 \mathrm{~Hz}$. Therefore, the center frequency could be efficiently found as well as the gain and bandwidth. For the final preamp used, the values were:

$$
\begin{aligned}
\text { fo } & =22.09 \mathrm{~Hz} \\
\text { bandwidth } & =0.04 \mathrm{~Hz} \\
\text { gain at fo } & =2300 \\
Q & =550
\end{aligned}
$$

Initial experiments were conducted by replacing the rear quartz window with a glass slip covered with carbon black. This provided a blackbody for energy absorption so that the actual response of the cell, microphone and amplifier system could be studied while applying pulsed light from any source. 
In order to assess the usefulness of the method, a system similar to that of Hawley and Ingle (ref. 27) was used. (See Fig. 4.)

Purified nitrogen was used because of its relative inertness to the excited mercury atom. A regulator and needle valve were used to fill the fixed volume reservoir to a set pressure before each run. This was done by closing the lower three-way stopcock and opening the needle valve until the reservoir reached the desired pressure. The needle valve was then closed. A one ml sample was then injected through the rubber septum followed by $0.2 \mathrm{ml}$ of a $\mathrm{SnCl}_{2}$ solution $\left(1 \% \mathrm{w} / \mathrm{v} \mathrm{SnCl}{ }_{2}\right)$ to reduce the mercury. By opening the lower stopcock, a fixed amount of nitrogen bubbled through the fritted glass and sample and carried the reduced mercury vapor through the drying tube into the detection cell. The cell could then be drained and washed by opening the upper stopcock to the atmosphere and the lower one to a vacuum flask. Before injecting the sample, the entire system was purged with nitrogen by opening both the lower stopcock and the needle valve. This was done to eliminate oxygen as much as possible because the excited state of mercury reacts with it, forming mercuric oxide. For the same reason, water vapor must be eliminated from the cell as completely as possible, accomplished by a magnesium perchlorate drying tube. 
RUBBER

SEPTUM

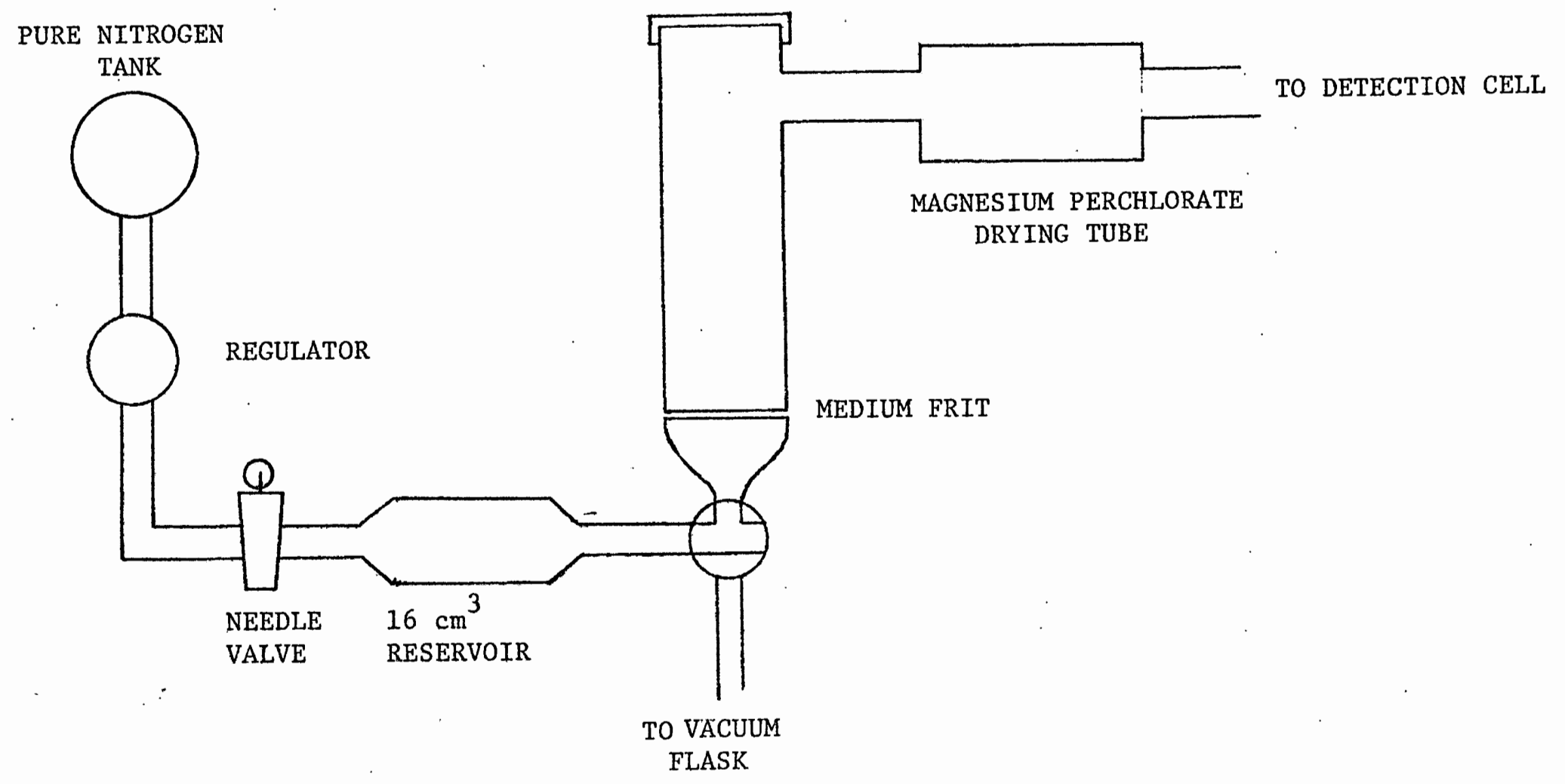

Figure 4: Sample Reduction Chamber 
CHAPTER IV

RESULTS AND DISCUSSION

The cell was tested initially to determine its absolute noise characteristics. In very quiet surroundings, with no light entering the cell, a background noise level of about $2 \mathrm{mV}$ pp was found.

With the microphone disconnected and no input to the amplifier, there was still about $2 \mathrm{mV}$ pp of noise present. Thus, the background noise, which could be due to a combination of general amplifier noise, thermal noise across the $5 \mathrm{M} \Omega$ dropping resistor and Brownian motion of the diaphragm (4), was attributed mostly to the thermal noise within the resistor. A calculation showed that at the bandwidth and amplification used, the thermal noise was, in fact, about this value.

In the laboratory, however, the noise level varied from 4 to $8 \mathrm{mV} \mathrm{pp}$. This was attributed to the high background acoustic noise within the building produced by ventilation and hood fans as well as random noises such as closing doors and dropped objects:

With the detection cell filled with dry nitrogen, which is optically transparent at $253.7 \mathrm{~nm}$, the pulsed light was then allowed to enter the cell to determine the background signal level. Two different lamp arrangements were used. Some measurements were made with the mercury lamp about seven $\mathrm{cm}$ from the quartz window and the lens about half way between the window and the lamp. The background signal in this case was unnoticeable above the noise level. The lamp was also placed about one $\mathrm{cm}$ from the window without using the lens. Although this 
allowed about a fifty percent light intensity increase to enter the cell, it also gave a background noise level of about $9 \mathrm{mV}$. This was attributed to absorption on the interior surface of the cell and at the joining interfaces of the windows due to the increased incident angle.

In order to estimate the response to mercury vapor, a small utube was connected to the cell inlet. This tube contained tiny droplets of mexcury. By flowing nitrogen through this tube and then into the detection cell, a mercury pressure of about 0.002 torr was produced. At a lamp current of $40 \mathrm{ma}$, a signal of about $1000 \mathrm{mV}$ was produced, which decreased as pure nitrogen was flushed through the system. The results of these initial tests showed that the technique could be used to detect mercury and, in fact, might be extremely sensitive. Estimates using the ideal gas law showed that approximately $100 \mathrm{ng}$ of mercury within the cell produced a very strong signal and that detection limits based on this value alone would be well below one nanogram.

By using the previously described reducing chamber, the response of the system to actual mercury solutions was investigated. In one series of experiments, in which the lamp was used with the lens, the results of Figure 6 were obtained. The results were linear, although in some experiments, the reproducibility was not exceptional. For instance, when a repeated sample of $2.5 \mu \mathrm{g} / \mathrm{l} \mathrm{Hg}$ was run, signal levels of $33,27,41,40$ and $38 \mathrm{mV}$ were obtained. The differences were probably caused by either sample entry variations or adsorption or desorption within the system, such as in the drying tube. An estimate of the 
detection limits where the signal is equal to the lowest peak-topeak noise level would be about $0.13 \mu \mathrm{g} / 1$. This noise level is shown on Figure 5, as well as the standard deviation based on the lease reproducible series. After some proficiency had been acquired, better results were obtained, as the points plotted in Figure 5 show.

The detection limits of mercury by this simple system can be compared to the limits by other means. Normal atomic absorption gives limits on the order of $0.5 \mathrm{mg} / 1$, however by using elaborate techniques, results with detection limits of $1 \mathrm{ng} / 1$ have been reported (27). Most cold vapor techniques, however, give results of about $0.1 \mu \mathrm{g} / 1$. So a mercury detection system based on this method, even with its simplicity, compares favorably with other methods, and with modifications in design could very well do better. 


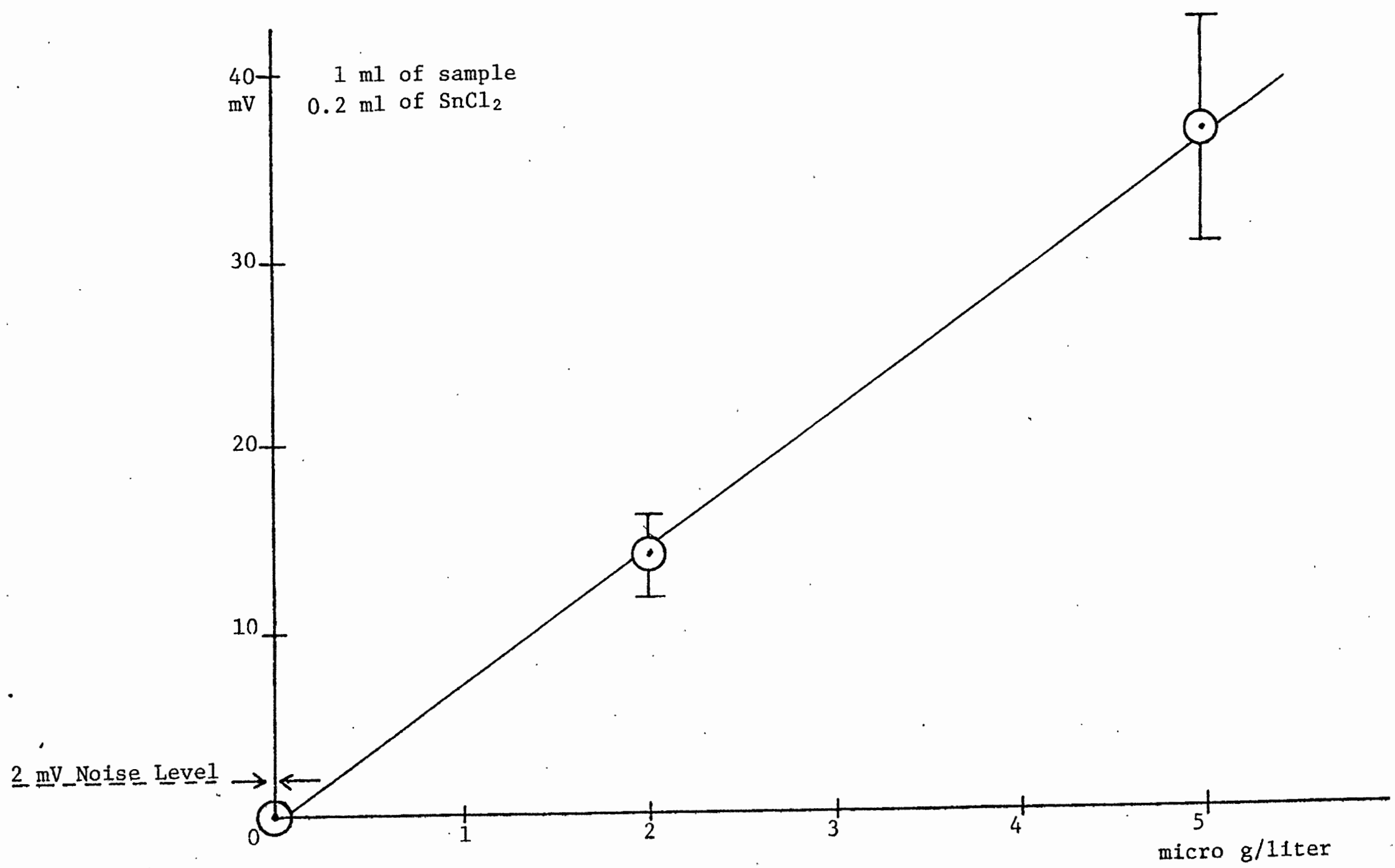

Figure 5: Signal Response vs. Mercury Concentration 


\section{APPENDIX A}

COLLISION OF Hg ATOMS WITH $\mathrm{N}_{2}$ MOLECULES

The number of collisions per second for an atom of $\mathrm{Hg}$ with surrounding $\mathrm{N}_{2}$ can be approximated using the equation

$$
z_{\mathrm{HgN}_{2}}=\frac{\pi \mathrm{d}^{2} \mathrm{HgN}_{2} \overline{\mathrm{C}}_{\mathrm{HgN}_{2}} \mathrm{~N}_{\mathrm{N}_{2}}}{\mathrm{~V}} \quad \text { (ref. 25) }
$$

where $\quad z_{\mathrm{HgN}_{2}}=$ the collisional frequency

$$
\begin{aligned}
& \mathrm{d}_{\mathrm{HgN}_{2}}=\begin{array}{l}
\text { sum of the effective diameters of the } \\
\text { two colliding species }
\end{array} \\
& \overline{\mathrm{C}}_{\mathrm{HgN}_{2}}=\text { speed of } \mathrm{Hg} \text { relative to } \mathrm{N}_{2} \\
& \frac{\mathrm{N}_{\mathrm{N}}}{\mathrm{V}}=\text { molecules of } \mathrm{N}_{2} \text { per unit volume }
\end{aligned}
$$

For quenching of the ${ }^{3} \mathrm{P}_{1}$ excited state of $\mathrm{Hg}$, the effective cross sectional area, $\sigma^{2}$, has been determined to be about $0.192 \mathrm{x}$ $10^{-16} \mathrm{~cm}^{2}$ (ref. 26). This gives an effective diameter for the $\mathrm{N}_{2}$ molecule of $\mathrm{d}_{\text {eff, }} \mathrm{N}_{2}=4.9 \times 10^{-11} \mathrm{~m}$. Using the diameter of $\mathrm{Hg}$ as $\mathrm{d}_{\mathrm{Hg}}=0.36 \times 10^{-9} \mathrm{~m}$ (ref. 26), one can calculate

$$
\mathrm{d}_{\mathrm{HgN}_{2}}=\left(\mathrm{d}_{\mathrm{N}_{2}}+\mathrm{d}_{\mathrm{Hg}}\right) / 2=\frac{40.9 \times 10^{-11}}{2} \mathrm{~m}
$$

The relative velocity, $\overrightarrow{\mathrm{C}}_{\mathrm{HgN}_{2}}$, can be calculated from

$$
\overline{\mathrm{C}}_{\mathrm{HgN}_{2}}=\sqrt{\frac{8 \mathrm{RT}}{\pi \mu}}
$$


where $\mu$ is the reduced mass

$$
\mu=\frac{\mathrm{MHg}_{\mathrm{Hg}} \times \mathrm{M}_{2}}{\mathrm{M}_{\mathrm{Hg}}+\mathrm{M}_{N_{2}}}=\frac{(200)(28)}{228}=24.6 \mathrm{gm} / \mathrm{mole} .
$$

so $\quad \overline{\mathrm{C}}_{\mathrm{HgN}_{2}}=5.07 \times 10^{2} \mathrm{~m} / \mathrm{sec}$.

The number of $\mathrm{N}_{2}$ molecules per unit volume is

$$
\frac{\mathrm{N}_{\mathrm{N}_{2}}}{\mathrm{~V}}=2.69 \times 10^{25} \text { molecules } / \mathrm{m}^{3}
$$

With the above values, one gets

$$
\begin{aligned}
{ }_{\mathrm{HgN}_{2}} & =1.8 \times 10^{9} \mathrm{sec}^{-1} \\
t & =\frac{1}{{ }^{\mathrm{HgN}_{2}}}=5 \times 10^{-10} \text { sec per collision. }
\end{aligned}
$$




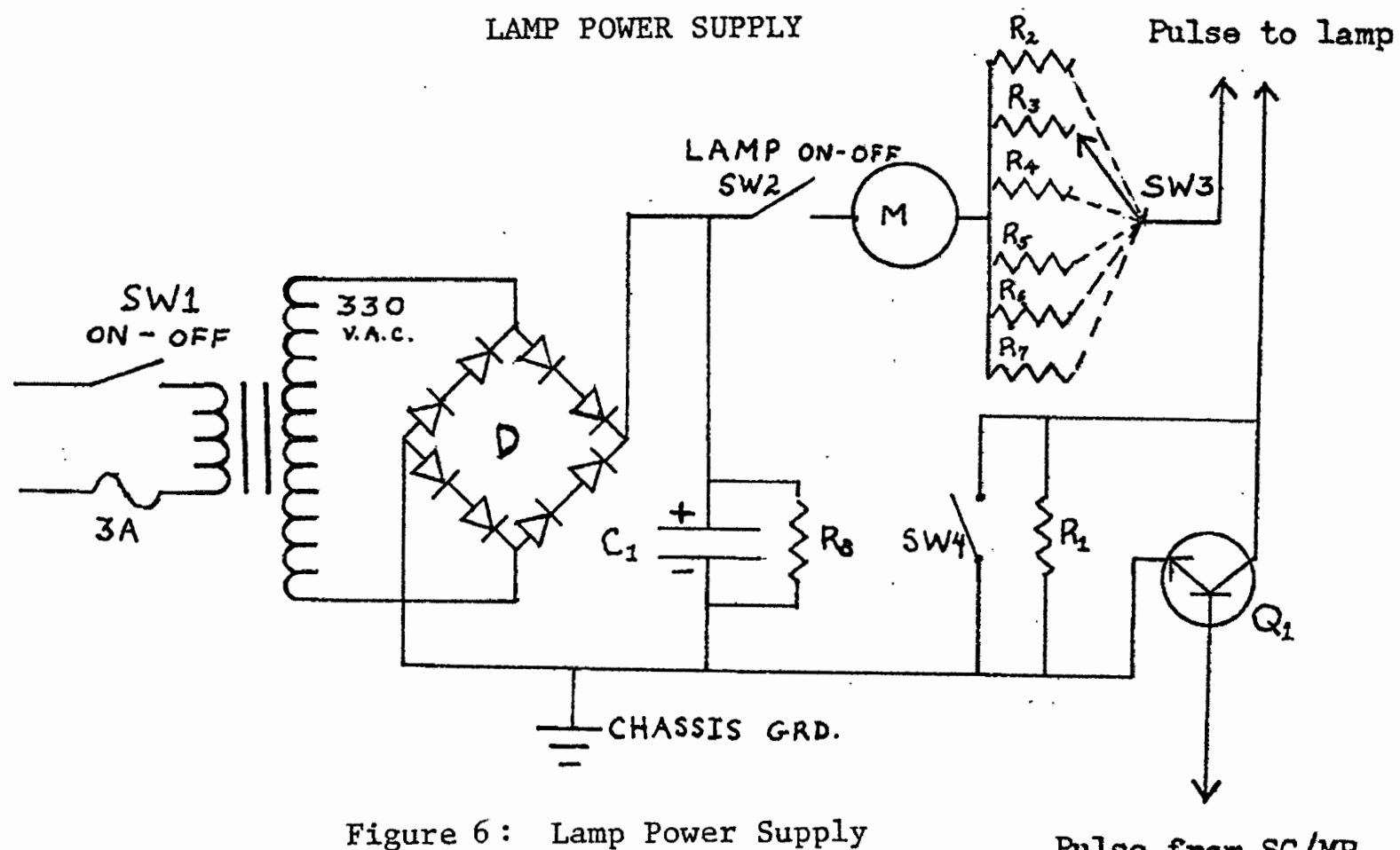

Figure 6: Lamp Power Supply

Pulse from $S C / M P$

$$
\begin{array}{ll}
\mathrm{D}-\text { Diodes, } 4005(600 \mathrm{~V} \mathrm{PIV}) & \mathrm{R}_{5}-25 \mathrm{~K} \\
\mathrm{Q}_{1}-\mathrm{BU} 204,3 \mathrm{~A}, 1300 \mathrm{~V}, & \mathrm{R}_{\dot{6}}-15 \mathrm{~K} \\
\mathrm{R}_{1}-310 \mathrm{~K} & \mathrm{R}_{\overline{7}}-37.5 \mathrm{~K} \\
\mathrm{R}_{2}-4 \mathrm{~K} & \mathrm{C}_{1}-15 \mathrm{uF}, 3000 \mathrm{~V} \\
\mathrm{R}_{3}-15 \mathrm{~K} & \mathrm{R}_{8}-10 \mathrm{M} \Omega \\
\mathrm{R}_{4}-20 \mathrm{~K} & \mathrm{M}-\text { Meter, } 65 \text { ma full scale }
\end{array}
$$

The switching pulse for transistor $Q_{1}$ was produced by the SC/MP (See Appendix D). switch.

Lamp current was selected by switch SW3, a multiposition rotary

Pulsed or continuous operation was made with SW4 i 
APPENDIX C

\section{AMPLIFIER CIRCUITS}

1) Preamplifier

The preamplifier used is shown below.

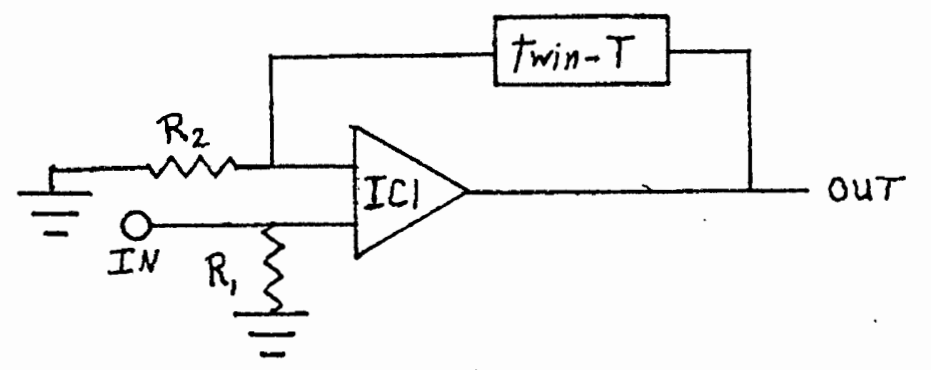

$$
\begin{aligned}
& I C 1-L F 356 H \text { (National) } \\
& R_{1}-5 M \Omega \\
& R_{2}-580 \Omega
\end{aligned}
$$

The twin-T feedback network was as follows.

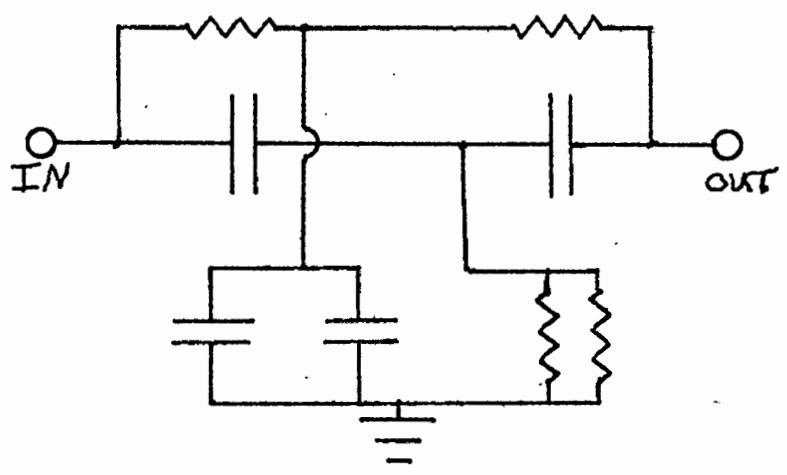

ALL $R=30.88 \mathrm{~K} \Omega$

ALL $C=0.2324 \mu \mathrm{F}$

Figure 8: Twin-T Filter

All resistors and capacitors were matched as well as possible. The amplifier's response was found to be:

$$
\begin{array}{rlrl}
\mathrm{f}_{\mathrm{O}} & =22.09 \mathrm{~Hz} & \text { bandwidth } & =0.04 \mathrm{~Hz} \\
\text { gain } & =2300 & \mathrm{Q} & =550
\end{array}
$$


2) Lock-in Amplifier

Figure 9 is the schematic for the lock-in amplifier used.

After a short period for warm up, the output of IC2 was monitored on an oscilloscope with the input grounded. The trimming resistors of IC1 and IC2 were then adjusted to give an even output of zero volts. IC3 was then adjusted to give a zero output.

With a small d.c. input, the waveform of IC2 should then be a square wave equally spaced about zero. This is averaged out by the low pass filter of $R 9$ and $C 1$ to a zero volt input to IC3.

Only a signal with exactly the frequency of the gating operation. will produce a d.c. signal at the output. Any other frequencies will be averaged out to zero. Signals which are exactly of the gating frequency but $90^{\circ}$ phase shifted will also cause zero output.

The circuit used was a modified absolute value detector with analog gates, GI and G2 replacing diodes. It was these gates which were operated by the SC/MP controlling pulses. 


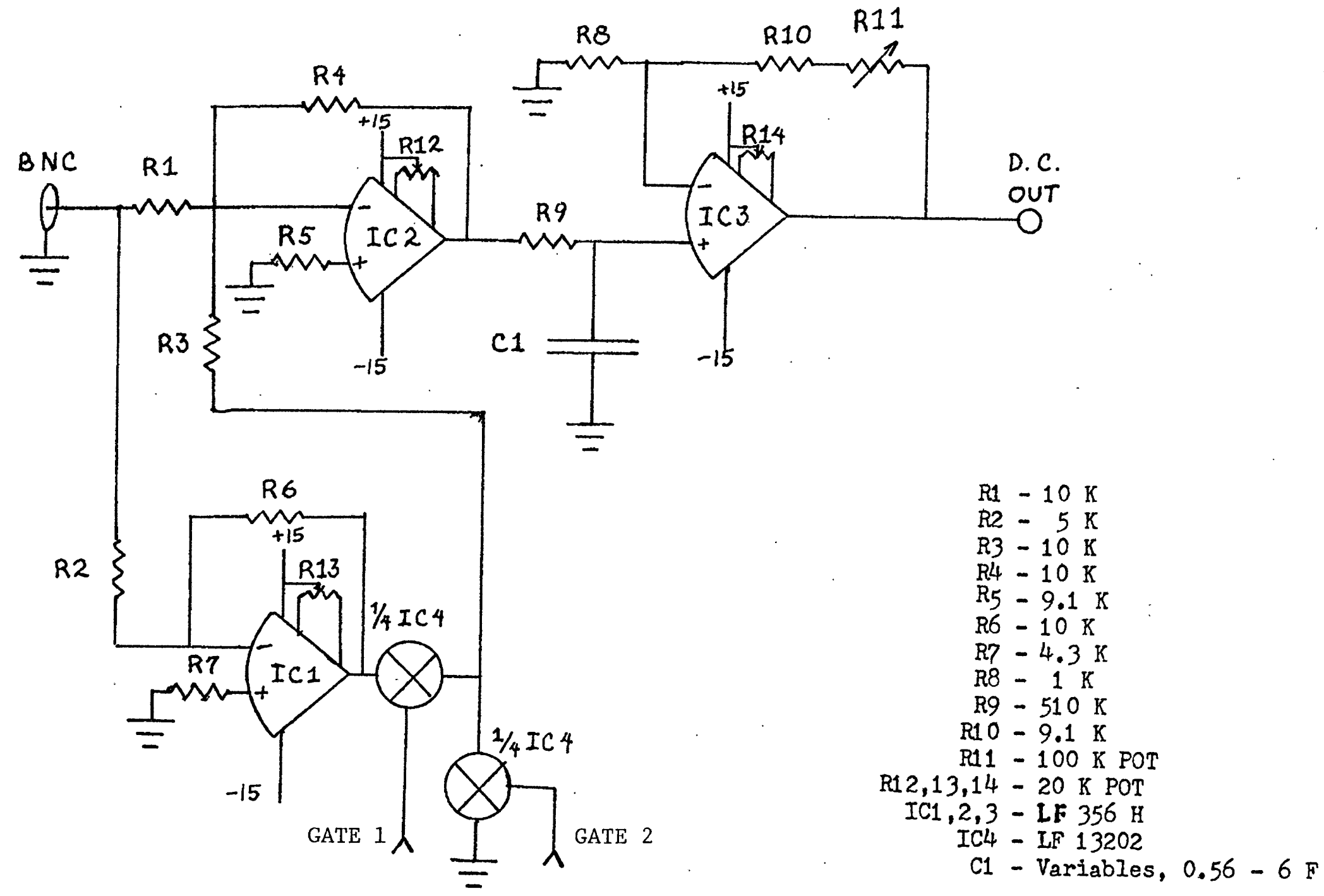

FROM SC/MP

Figure 9; Lock-in Amplifier 
APPENDIX D

SC/MP PULSE CONTROLLER

The SC/MP microprocessor was used to generate the controlling pulses for the lamp and lock-in amplifier. The status register of the SC/MP contains three bits, FO, F1 and F2, which are connected to exterior pins. Thus, by setting or resetting these bits, one may control exterior devices. The signals generated are TTL compatible, and on the LCDS they are buffered for external use.

For a 50\% duty cycle lamp pulse, the corresponding pressure pulse will be about $90^{\circ}$ phase shifted (see Figure 10 ).

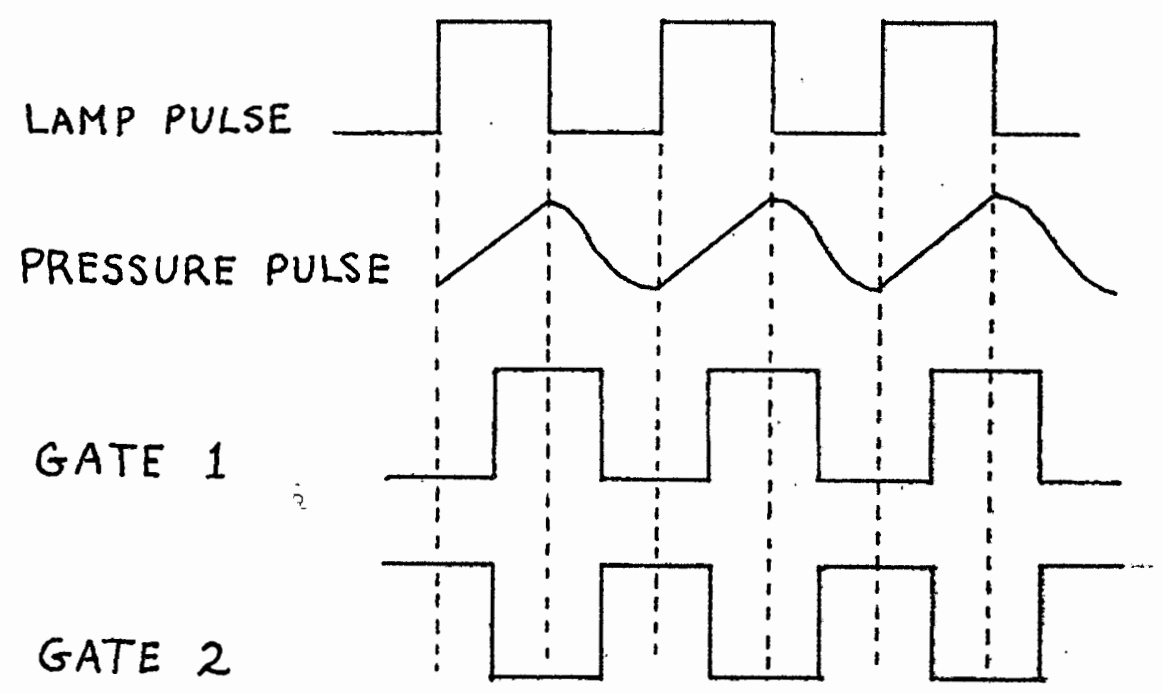

Figure 10: Phase Relationship of Pulses

Thus, if a controlling signal is generated for the lamp by FO, one 
would want $F 1$ and $F 2$, which control the lock-in operations, to set or reset $90^{\circ}$ later. This is implemented by the program in Table 1. The program represents only one half of a full cycle, but with a $90^{\circ}$ shift, the wave will be symmetrical. A jump instruction at the end will therefore generate the three desired pulse trains until the microprocessor is halted.

The period of the wave form is determined by the delay instructions in lines 14 and 20. The time generated by this instruction depends on the contents of the accumulator, which must be loaded appropriately before the DLY instruction (IDI in lines 13 and 19) as well as the operand of the DLY instruction itself. Instruction length, as well as how to calculate delay times may be found in the SC/MP Technical Bulletin (23).

Therefore, once the program has been loaded, one only has to change the contents of memory addresses 8006 and $800 \mathrm{~F}$ for small changes in period length or those of 8008 and 8011 for larger time changes.

These pulses will, of course, produce electromagnetic radiation of exactly the lock-in frequency. This mostly was eliminated by wrapping the microphone and preamp with aluminum foil. However, any stray signal picked up was fortunately cancelled because a lock-in amplifier does not respond to signals of the same frequency which are $90^{\circ}$ out of phase.

When determining the frequency response of the band-pass preamp, one of the signals produced by the SC/MP was used. Since this was a square wave of $3.5 \mathrm{Vpp}$, the primary sine wave which is produced will 
be $\frac{4}{\pi}(3.5)=4.44 \mathrm{Vpp}$. This was first attenuated by a $700 \mathrm{~K}$ resistor in series with a $260 \Omega$ resistor before applying it to the preamp input. Thus, a $1.6 \mathrm{mVpp}$ sine wave of the frequency of interest. was being applied which allowed the overall gain response to be calculated. 


\section{TABLE I}

GENERAL PROGRAM FOR CONTROL PULSES

SC/MP ASSEMBLER

\begin{tabular}{ll}
1 & \\
3 & \\
4 & \\
5 & \\
6 & \\
7 & \\
8 & \\
9 & \\
\hline & 8000 \\
1 & 8002 \\
1 & 8004 \\
13 & 8005 \\
14 & 8007 \\
15 & 8009 \\
17 & $800 \mathrm{~A}$ \\
17 & $800 \mathrm{~B}$ \\
$1900 \mathrm{D}$ \\
\hline 9 & $800 \mathrm{E}$ \\
\hline 1 & 8010 \\
\hline 2012 \\
8013 \\
\hline 3 & 8015 \\
\hline 4 &
\end{tabular}

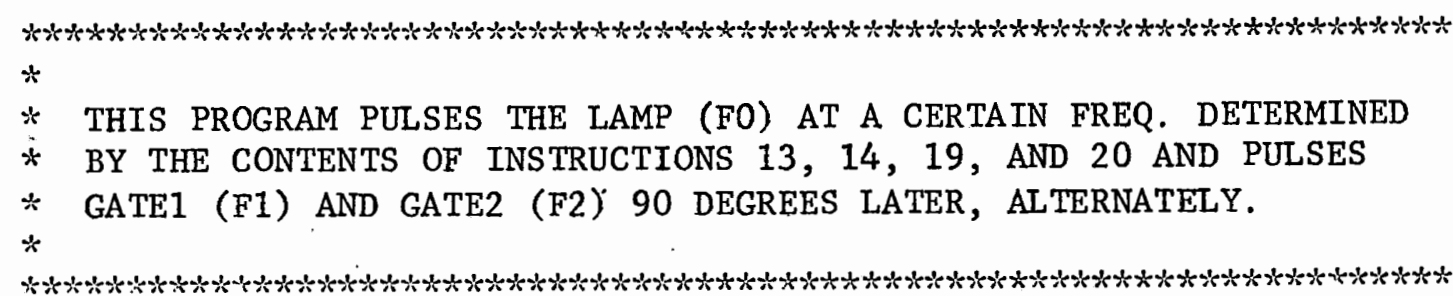


For the final preamp circuit used (see Appendix C), it was found that the assembly language program of Table II would generate the desired pulse frequency.

TABLE II

PROGRAM FOR $22.093 \mathrm{~Hz}$ PULSES

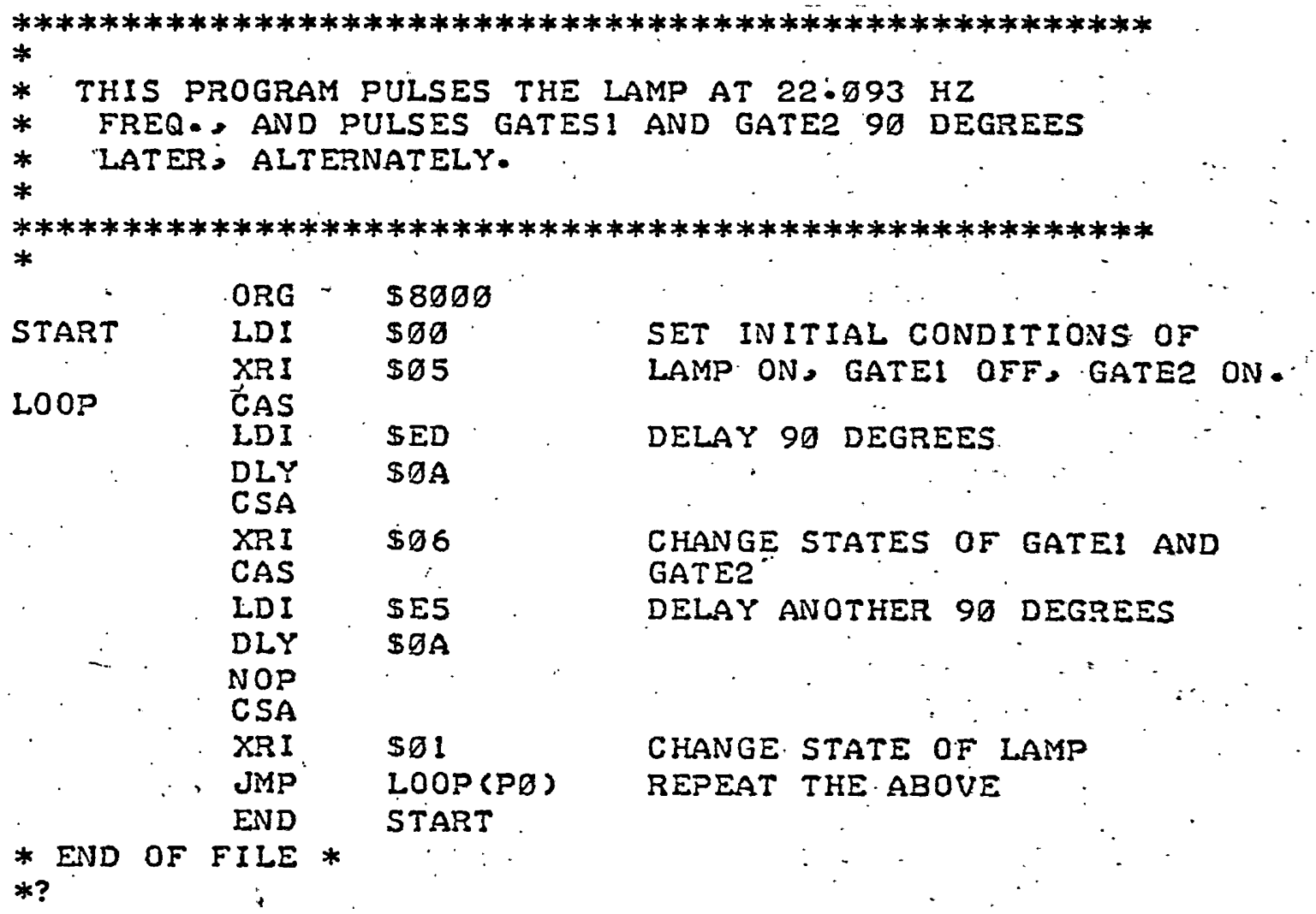




\section{B IBLIOGRAPHY}

1. W.R. Harshbarger and M.B. Robin, Accounts of Chemical Research, $\underline{6}$, 329 (1973).

2. M.J. Adams, A.A. King and G.F. Kirkbright, The Analyst, 101,73 (1976).

3. L. Rosengren, App. Optics, 14, 1960 (1975).

4. L.B. Kreuzer, J. App. Phys., 42, (1971).

5. Robin, M.B., personal communication, Feb., 1977.

6. C.K.N. Patel and R.J. Ker1, App. Phys. Lett., 30, 578 (1977).

7. C.F. Dewey Jr., R.D. Kamm, and C.E. Hackett, App. Phys. Lett., 23, 633 (1973).

8. R.D. Kamm, J. of App. Phys., 47, 3550 (1976).

9. M.J. Adams, B.C. Beadle, A.A. King and G.F. Kirkbright, The Analyst, 101,533 (1976).

10. M.B. Robin, J. of Luminescence, 12, 139 (1976) •

11. D.M. Munroe and H.S. Reichard, Amer. Lab., 9 (2), 119 (1977).

12. A. Rosencwaig, Phys. Today, 28, 23 (1975).

13. A. Rosencwaig, Anal. Chem., 47, 592A (1975).

14. A. Rosencwaig and A. Gersho, J. of App. Phys., 47, 64 (1976).

15. W. Lahmann, H.J. Ludewig and H. Welling, Anal. Chem., 49, 549 (1977).

16. W.R. Harshbarger and M.B. Robin, Chem. Phys. Lett., 21, 462 (1973).

17. M.B. Robin and N.A. Kuebler, J. Am. Chem. Soc., 97, 4822 (1975).

18. G.C. Wetsel, Jr. and F.A. McDonald, App. Phys. Lett., 30, 252 (1977).

19. J.D. Winefordner and R.C. Elser, Anal. Chem., 43, 24A (1971).

20. G.F. Kirkbright and M. Sargent, Atomic Absorption and Fluorescence Spectroscopy, Academic Press Inc., London, 1974. 
21. L.B. Kruezer, personal communication, May, 1977.

22. M.B. Robin, personal communication, Nov., 1976.

23. SC/MP Technical Description, National Semiconductor Corp., Santa Clara, CA.

24. P.A. Temple, Am. J. of Phys., 43, 801 (1975).

25. W.J. Moore, Physical Chemistry, 4th Ed., Prentice-Ha11, Inc., Englewood Cliffs, New Jersey.

26. W.A. Noyes and P.A. Leighton, The Photochemistry of Gases, Dover Publications, Inc., New York.

27. J.E. Hawley and J.D. Ingle, Jr., Anal. Chem., 47, 719 (1975). 